\title{
The Villalbeto de la Peña Meteorite: Raman Spectroscopy and Cathodoluminescence of Feldspar
}

\author{
Garcia-Guinea $^{\mathrm{a}}$, J., L. Sanchez-Muñoz ${ }^{\mathrm{b}}$, J. L. Tormo ${ }^{\mathrm{a}}$, E. Crespo-Feo ${ }^{\mathrm{a}}$, \\ J. Ruiz-Perez ${ }^{\mathrm{c}}$, A.I. Martin-Herrero ${ }^{\mathrm{d}}$, A. Cremades ${ }^{\mathrm{e}}$ \\ "Museo Nacional Ciencias Naturales, Jose Gutierrez Abascal 2, Madrid 28006, Spain,; \\ ${ }^{b}$ CIEMAT. Av. Complutense 22, Madrid 28040, Spain, \\ ${ }^{c}$ Centro de Biologia Molecular, CSIC-Universidad Autónoma de Madrid, 28049 Cantoblanco, Madrid, \\ Spain. 'Seminario de Ciencias Planetarias, Universidad Complutense de Madrid, 28040 Madrid, Spain. \\ ${ }^{e}$ Dpto Fisica Materiales, Facultad de Fisicas, Universidad Complutense de Madrid, 28040, Spain.
}

\begin{abstract}
This paper mainly focuses on the spatial distribution of plagioclase phases observed by Raman and spectra cathodoluminescence (CL) emission of in the Villalbeto de la Peña meteorite. Initially, we collected fragments countryside to determine the strewn field area and to perform spot chemical analyses by electron microprobe for the classification of the specimens (L6 Chondrite). Furthermore, the hyperspectral Raman mapping allow us identify amorphous Maskelynite feldspar in plagioclase micro-fissures since it is a molecular technique. The spectra CL emission bands observed at circa 290, 340, 390, 440, 510, 640 and $780 \mathrm{~nm}$ are characteristic in aluminosilicate lattices providing additional data on $\mathrm{H}^{+}, \mathrm{OH}^{-}$and $\mathrm{H}_{2} \mathrm{O}$ and $\mathrm{Na}^{+}$ self-diffusion along interfaces $(290 \mathrm{~nm})$, on strained $\mathrm{Si}-\mathrm{O}$ bonds $(340$ and $650 \mathrm{~nm})$, on $\left[\mathrm{AlO}_{4}\right]^{\bullet}$ centers $(380-390 \mathrm{~nm}$ and $420-440 \mathrm{~nm})$, on $\mathrm{O}^{-}-\mathrm{Si} \ldots \mathrm{M}^{+}$centers $(510 \mathrm{~nm})$ and on substitutional $\mathrm{Fe}^{3+}$ in aluminum positions $(740-800 \mathrm{~nm}$ broad band). The $\mathrm{CL}$ and hyperspectral Raman techniques coupling demonstrates that the Villalbeto meteorite was shock-metamorphosed from the amorphous Maskelynite presence in Plagioclase fissures and from the strained $\mathrm{Si}-\mathrm{O}$ bonds at room temperature.
\end{abstract}

Keywords: Spectra-Cathodoluminescence, Hyperspectral-Raman, Maskelynite, VillalbetoMeteorite, Plagioclase, Feldspars, Luminescence.

\section{INTRODUCTION}

The fall of the Villalbeto de la Peña

the best documented in history for which atmospheric and orbital trajectory, strewn field area, and recovery circumstances have been described in detail [1-2] (Fig. 1). Additional details on the bulk chemistry [3] and the bulk luminescence [4] were later provided. Moreover, the intrinsic complexity of composition, distribution and structural states of plagioclase crystals in L6 chondrite meteorites [5], such as the Villalbeto feldspars case, suggested us to perform this study by Electron Probe Microanalyses (EPMA), spatially-resolved spectra Cathodoluminescence (CL) and Hyperspectral-Raman contour-plot micro-analyses (Raman), exploring the Maskelynite-Plagioclase distribution of the studied fragments and the possible 
between relationships the CL emission bands and the common structural plagioclase features. The UV-blue region of the feldspar spectrum displays numerous broad bands, which are generally discussed in terms of intrinsic defects. In the case of intrinsic defects particularly, precise models are probably unfeasible because of the variety of lattice site distortions which arise in such a complex and variable mineral system. In despite of this difficulty, we try to manage possible defect-emission linkages on the basis of previous references and the most common plagioclase defects.
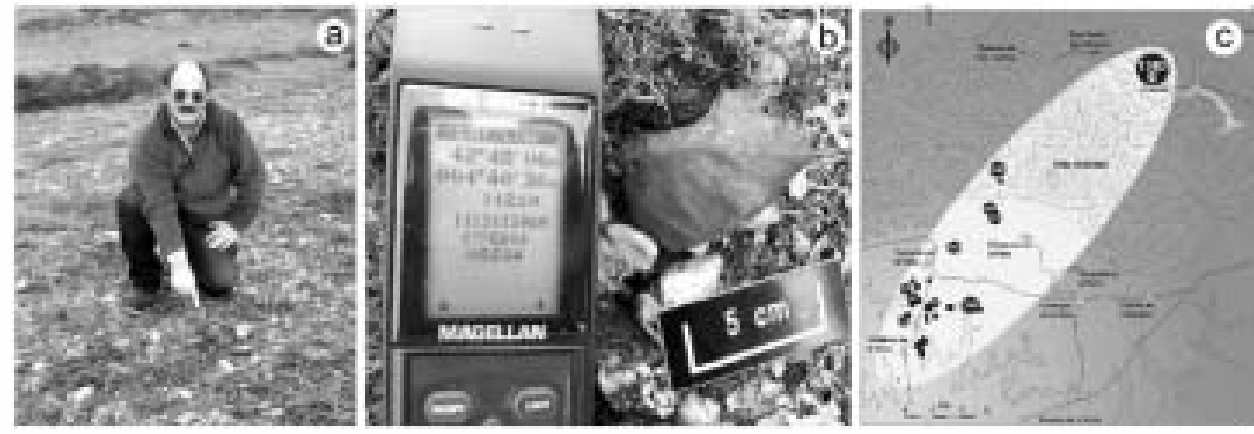

FIGURE 1. (a) First author (Garcia-Guinea) finding a fragment, (b) Detail of the meteorite in its original position, (c) Strewn field area outlined on the basis of 32 collected fragments together with their GPS positions.

\section{EXPERIMENTAL}

We study in polished sections of the L6-chondrite specimens collected by ourselves in Villalbeto and stored as international type reference samples in our National Museum of Natural Science of Madrid which also keeps circa the $95 \%$ of all the Spanish meteorite fragments. The Electron Probe Microanalyses (EPMA) analyses were performed by a Jeol Superprobe JXA-8900M and by Environmental Scanning Electron Microscopy with X-ray Dispersive Spectrometry probe (ESEM-EDS) in an Inspect-S ESEM of the FEI company. The hyperspectral Raman contour plots were performed using a new ThermoFischer Raman Microscope with one micron spatial resolution and a laser source at $532 \mathrm{~nm}$. The hot CL spectra of plaglioclase grains were obtained by SEM-CL in a Hitachi S2500 electron microscope. Light emissions were focused with lens attached to the microscope window, and a light guide was used to feed the light into the CCD camera and the CL images were recorded using a Hamanatsu R-928 photomultiplier. The CL spectra were recorded with a Hamamatsu PMA-11 CCD cam-era. Cold CL images of Villalbeto feldspars distribution were taken in a optical CL 8200 MK4 system made by Cambridge Image Technology Ltd, with an electron beam exciting at $16 \mathrm{kV}$ and a current of $0.5 \mathrm{~mA} / \mathrm{s}$. 


\section{RESULTS AND DISCUSSION}

From the intensity of blue CL and BSE contrast in SEM images (Fig. 3), two different regions of feldspar composition have been observed: i) Maskelenite and Narich feldspars forming mixtures at a level lower than the resolution of optical microscopy techniques forming like-veins between other crystals and intergrowths with pyroxene; ii) extended volumes with homogeneous Na-rich feldspar crystalline structure. The results of the EPMA 45 spot analysis on feldspar phases are shown in both, Table 1, as some representative analyses of feldspar, and Figure 2, which displays the ternary $\mathrm{Na} 2 \mathrm{O}-\mathrm{K} 2 \mathrm{O}-\mathrm{CaO}$ compositions of Villalbeto feldspar samples. The Na-rich feldspars were also analyzed by transmission electron diffraction (TEM) and selected area electron diffraction (SAED) along [001] zone axis, in a microscope with an EDAX facility to correlate chemical, structural and micro-structural data. No twinning were identified in TEM images, diffraction spots do not show splitting, and a regular circular shape allow us to measure the $\gamma^{*}$ angle being lower than $90^{\circ}$, indicating a high or intermediate albite local ordering scheme in the Si/Al distribution.

TABLE 1. Spot Electron Probe Microanalyses of the most representative phases taken on feldspar zones of the Villalbeto L6 Chondrite.

\begin{tabular}{|l|c|c|c|c|c|}
\hline & Bytownite & Albite & Oligoclase & Maskelenite & Maskelenite \\
\hline $\mathrm{SiO}_{2}$ & 64.63 & 64.87 & 66.15 & 67.84 & 68.81 \\
\hline $\mathrm{Al}_{2} \mathrm{O}_{3}$ & 17.58 & 21.18 & 22.87 & 23.28 & 22.96 \\
\hline $\mathrm{FeO}$ & 1.41 & 0.44 & 0.54 & 0.31 & 0.66 \\
\hline $\mathrm{MnO}$ & 0.01 & 0.00 & 0.08 & 0.00 & 0.00 \\
\hline $\mathrm{MgO}$ & 3.76 & 0.01 & 0.02 & 0.00 & 0.03 \\
\hline $\mathrm{CaO}$ & 8.20 & 2.36 & 2.51 & 2.24 & 2.16 \\
\hline $\mathrm{Na}_{2} \mathrm{O}$ & 2.75 & 9.91 & 6.87 & 3.99 & 2.67 \\
\hline $\mathrm{K}_{2} \mathrm{O}$ & 1.14 & 0.27 & 0.66 & 1.82 & 1.71 \\
\hline $\mathrm{TiO}_{2}$ & 0.10 & 0.00 & 0.02 & 0.01 & 0.09 \\
\hline $\mathrm{NiO}^{\mathrm{Cr}} \mathrm{O}_{2}$ & 0.03 & 0.01 & 0.00 & 0.00 & 0.10 \\
\hline $\mathrm{P}_{2} \mathrm{O}_{5}$ & 0.15 & 0.00 & 0.00 & 0.00 & 0.02 \\
\hline $\mathrm{Total}$ & 0.03 & 0.02 & 0.03 & 0.00 & 0.00 \\
\hline
\end{tabular}




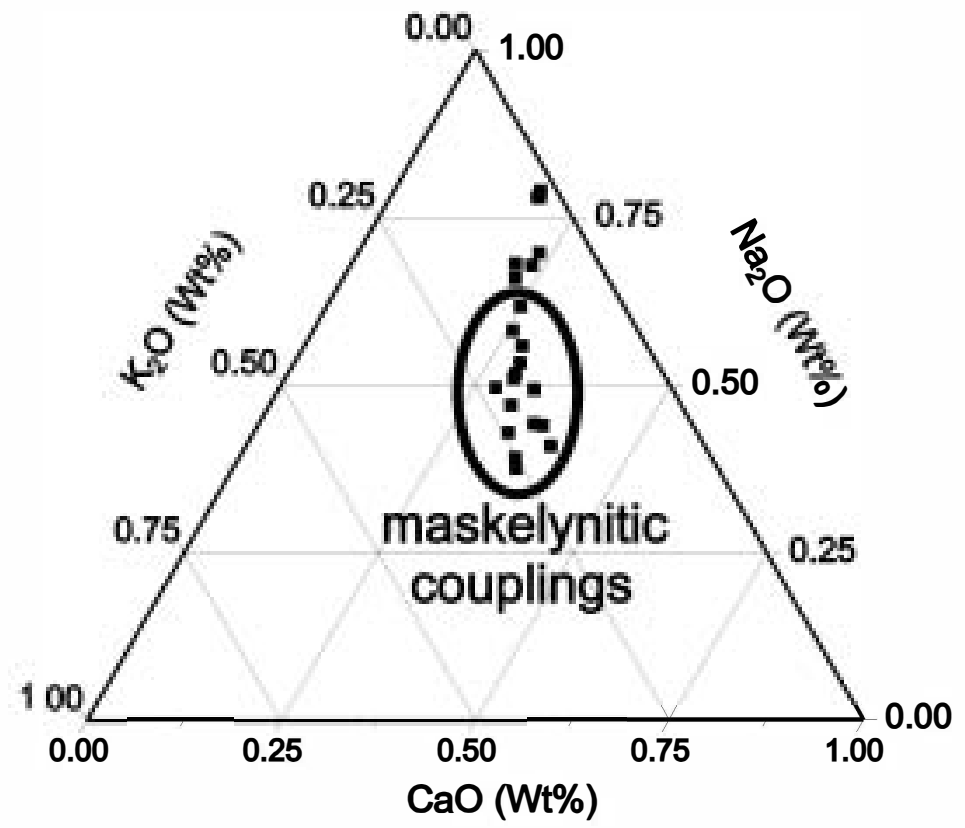

FIGURE 2. (a) Ternary alkalis plot $(\mathrm{K} 2 \mathrm{O}-\mathrm{Na} 2 \mathrm{O}-\mathrm{CaO})$ of the spot EMPA analyses depicting maskelenitic compositions since this region is commonly empty in terrestrial feldspar.

Maskelenite was easily identified by the lack of structure in the electron diffraction spectra. We infer that our experimental results on metastable proportional K-Ca-Na compositions, sited in the triangle center, could be partially amorphous Maskelenite, together with crystalline plagioclase species, e.g., bytownite, albite, oligoclase (Table 1). The meteorite luminescence is mainly produced by feldspars, Figure 3 a shows the cold CL plot distribution, as follows: (i) red spots, Bytownite with $\mathrm{Mn}^{2+}$ point defects in structural $\mathrm{Ca}$ positions, (ii) blue masses, Oligoclase with $\left[\mathrm{AlO}_{4}\right]^{\circ}$ defects, (iii) Maskelenite sodium glasses with low UV-blue emission. Figure 2b\&c displays the spatially-resolved hot CL spectra taken on the main feldspar masses observed under SEM in good agreement with the cold CL picture. A Hyperspectral Raman plot was also performed to explore the plagioclase crystal (Fig.3c and d). The maskelynite amorphous phase was mainly observed in the plagioclase fissures previously analysed in the ESEM microscope. The maskelynite Raman spectrum includes common peaks with plagioclases phases. Finally, Figure 3e depicts representative spectra CL taken from different regions on the feldspar areas. Fig $3 f$ displays a representative spectrum CL of plagioclase with resolved peak maxima at 295, 331, 393, 442, 514, 653 and 774 nm. 

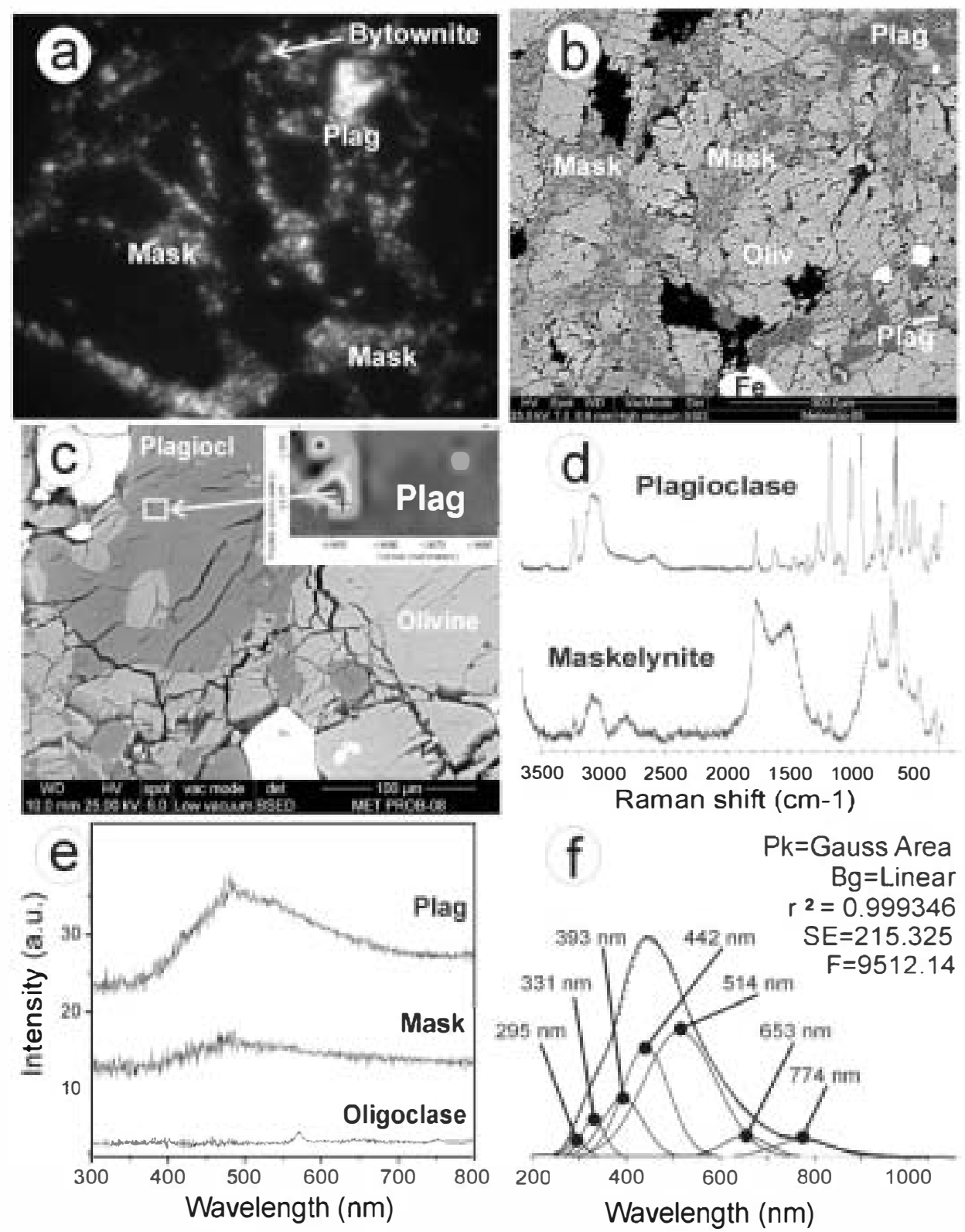

FIGURE 3. Villalbeto meteorite plagioclase feldspars: (a) Image of Cold CL by polarizing microscopy. ( b) Backscaterring SEM image showing the feldspars spatial distribution, (c) Detail of maskelenite in fissures under SEM and region explored by an hyperspectral Raman plot contour, (d)

Two representative Raman spectra of the plagioclasic phases, (e) CL spectra of some different plagioclase grains, (f) Deconvolution of a plagioclase CL spectrum exhibiting the classic spectra bands of plagioclase feldspars. 
According to the defect-emission linkages for feldspars reviewed by Krbetschek et al. [6], we suggest that Villalbeto plagioclase display the general position bands in feldspars at 290, 340, 390, 440, 510, 640 and $780 \mathrm{~nm}$ (Fig. 3f). (i) The $290 \mathrm{~nm} \mathrm{CL}$ emission is a irreversible thermolabile band of sodium plagioclase [7], which disappears with soft pre-heating, it has been also linked with metals $\mathrm{Pb}$ and $\mathrm{Tl}$ in amazonite fissures [8], all is true, since we test larger CL $290 \mathrm{~nm}$ emission in these hydrous zones of amazonite with metals, furthermore, it seems a better decisive factor to explain widespread emissions by collective feldspar features and not just only by scarce natural activators or rare elements; in the $290 \mathrm{~nm}$ case, common factors may be $\mathrm{H}^{+}, \mathrm{OH}^{-}$and $\mathrm{H}_{2} \mathrm{O}$ and $\mathrm{Na}^{+}$self-diffusion along interfaces. (ii) the $340 \mathrm{~nm}$ emission $\mathrm{CL}$ is only observed at room temperature in stressed silicate lattices, such as the cases of hatch-crossed microclines, or in near all silicates recording ionoluminescence at low temperature [9]. (iii) the $380-390 \mathrm{~nm}$ and $420-440$ were described in quartz [10] where prolonged high-temperature annealing of the samples in vacuum $\left(10 \mathrm{~h}\right.$ at $1400^{\circ} \mathrm{C}, 1$ $\mathrm{Pa}$ ) reduces the presence of ionic charge compensators at the $\mathrm{Al}$ sites and induces an intense $380 \mathrm{~nm}$ thermostimulated-luminescence (TSL) emission to $\left[\mathrm{AlO}_{4}\right]^{\circ}$ centers. Prolonged strong annealing of aluminosilicate lattices (quartz, feldspars, feldspathoids, zeolites, etc.) remove alkali ions and produce intense blue TSL emissions (around 430 $\mathrm{nm}$ ), these centers were also previously $\mathrm{Al}-\mathrm{O}^{-} \mathrm{Al}$ [11]. Plagioclase lattices may be sensitized, by thermal leakage of alkali ions, from very low temperature-time doses, (e.g. $80{ }^{\circ} \mathrm{C}$ for a few minutes to above $1400{ }^{\circ} \mathrm{C}$ for several months). These processes involve $\left.\mathrm{Na}^{+}, \mathrm{K}^{+}, \mathrm{OH}\right), \mathrm{H}^{+}$and $\mathrm{H}_{2} \mathrm{O}$ exchanges with the environment. (iv) the 510 emission $\mathrm{CL}$ band was associated with $\mathrm{O}^{-}-\mathrm{Si} \ldots \mathrm{M}^{+}$centers [12] being very common in framework silicates, (v) the red emission band at circa $650 \mathrm{~nm}$ is most intense in volcanic quartz specimens being associated with strained silicon-oxygen bonds [12] a similar stress could be found in strained meteorite plagioclase lattices such the Villalbeto case. Luminescence studies of feldspars have linked some impurity sites to specific emission bands, e.g. Fe with $720 \mathrm{~nm}$ or Mn to $560 \mathrm{~nm}$ emissions [13-15]. In Villalbeto plagioclase case, both emissions CL bands at $340 \& 650 \mathrm{~nm}$ points to strained $\mathrm{Si}-\mathrm{O}$ bonds, i.e., a possible tectonic origin for the fragments in accordance with other previous data reported indicating that Villalbeto meteorite was shockmetamorphosed [3].

\section{REFERENCES}

1. L. Llorca et al., Meteoritics \& Planet. Sci., 40, 795-804 (2005).

2. J.M. Trigo-Rodriguez et al., Meteoritics \& Planet. Sci., 41, 505-517 (2006).

3. J. Llorca et al., Meteoritics \& Planet. Sci., 41, A177-A182 (2007).

4. V. Correcher V. et al., NIM Phys Res. A. 580, 637-640 (2007).

5. Y. Nakamuta, and Y. Motomura, Meteoritics \& Planet. Sci., 34, 763-772 (1999).

6. M.R. Krbetschek, J. Götze, A. Dietrich, T. Trautmann, Radiat. Meas. 27,(5-6), 695-748 (1997).

7. J. Garcia-Guinea, J. Garcia-Guinea J, H.M. Rendell, L. Sanchez-Munoz, Radiat Protec Dosim 66, 39-398 (1996).

8. B.S. Gorobets, M.L. Gaft, A.M. Podolsky, Luminescence of Minerals and Ores. Ministry of Geology. Moscow. USSR (1989). 
9. J. Garcia-Guinea, V. Correcher, L. Sanchez-Munoz, A.A. Finch, D.E. Hole, P.D. Townsend, NIM \& Meth. Phys. Res. Section A 580, 648 - 651 (2007).

10. M. Martini, A. Paleari, G. Spinolo, A. Vedda, Phys Rev B Cond Matter 52(1), 138-142 (1995).

11. A.S. Marfunin, Spectroscopy, Luminescence and Radiation Centers in Minerals. Springer. Berlin (1979).

12. A.S. Marfunin, and L.V. Bershov, Dokl. Akad. Nauk. 193, 412- 414 (1970).

13. J. E. Geake, G. Walker, D. J. Telfer, A.A. Mills, Phil. Trans. R. Soc. London A 285, 403-- 408 (1977).

14. D.J. Telfer and G. Walker, Mod. Geology 6, 199-210 (1978).

15. A. A. Finch, D.E. Hole, P. D. Townsend P. D., Phys. Chem. Mineral. 30, 373-381 (2003). 